\title{
INHALATION THERAPY - APPROACHES AND CHALLENGES
}

\author{
SAYANI BHATTACHARYYA*, BHARANI S SOGALI
}

Department of Pharmaceutics, Krupanidhi College of Pharmacy, No: 12/1 Carmelaram Road, Chikka Bellandur, Varthur, Hobli, Carmelaram Post, Bengaluru - 560 035, Karnataka, India. Email:Sayanibh@gmail.com

Received: 05 December 2017, Revised and Accepted: 02 January 2018

ABSTRACT

Inhalation therapy is an effective way for local and systemic delivery of miscellaneous drugs for pulmonary and non-pulmonary diseases. The inhalation therapy aims to target specific cells or regions of the lung, bypassing the lung's clearance mechanisms and thereby providing high retention of the drug for longer periods. It helps in improved penetration of intravenously administered antibiotics into lung parenchymal tissue and bronchial secretions, and as a result, their potential systemic toxicity is reduced when given over prolonged periods of time. The advancement in device technology supports the development of more efficient therapy in the form of delivering finer particles into the lung in large doses. Therefore, meticulous daily management of lung disease, together with prompt, aggressive treatment of exacerbations can be achieved through inhalation to preserve lung function. This review summarizes the features of inhalation delivery devices, their advantages and limitations, challenges in formulation and brief description of novel technologies currently marketed.

Keywords: Lung, Inhalation, Target, Local delivery, Systemic delivery, Novel technologies.

(C) 2018 The Authors. Published by Innovare Academic Sciences Pvt Ltd. This is an open access article under the CC BY license (http://creativecommons. org/licenses/by/4. 0/) DOI: http://dx.doi.org/10.22159/ajpcr.2018.v11i4.24117

\section{INTRODUCTION}

The pulmonary route of administration has been selected as an effective route for the treatment of pulmonary and non-pulmonary diseases. The local and systemic delivery of drugs, proteins, peptides, and biotechnology products for the treatment of various diseases can be administered through pulmonary delivery. Lungs offer a huge surface area with abundant vasculature and thin air-blood barrier. This makes pulmonary delivery very useful for rapid absorption of drugs with the additional benefit of bypassing first pass metabolism. Local administration of drugs to the lungs offers several advantages, for patients suffering from pulmonary infections, asthma, and lung cancer $[1,2]$. The deposition pattern and efficacy of the inhalant are dependent on the proper apportionment of the formulation factors and design of the delivery device efficacy. Thus, the success and effectiveness of inhalation therapy greatly depend on parameters such as the drug formulation, design of the inhaler device, the patient condition, and availability of the drug at the intended site of deposition [3]. Practicing of inhalation therapy has been seen over thousands of years by ancient civilizations in Egypt, Greece, India, and People's Republic of China [4]. The approaches of administration through inhalation deliver the effective dose directly to the site of disease rather than administering much higher doses systemically. Localization of therapies help in economic utilization of the drug in smaller doses thus helps in reduction in systemic side effects with elevated drug concentration at the site of action, and reduction in the frequency of administration [5]. Recently, Center for Drug Evaluation and Research and Food and Drug Administration (FDA) have approved Cayston ${ }^{\mathrm{TM}}$ an inhalation solution for antibiotic Aztreonam for the treatment of pneumonia.

\section{MECHANISM, ADVANTAGES AND CHALLENGES INVOLVED IN THE DELIVERY OF INHALATION THERAPEUTIC DRUGS}

Lung offers numerous advantages as a delivery route for non-invasive drugs especially for localized therapy [2]. The presence of mucus, ciliated cells and macrophages in the respiratory airway systems provide hindrance in localization, penetration and absorption of drugs in the lung. The location of the deposited drugs in the airways determines the clearance mechanism of inhaled drugs. Alveolar macrophages protect the drugs that are deposited in the lower airways while drug localized at the upper airways are removed by ciliated cells in the epithelial region. The alveolar macrophages detect the presence of foreign particles, engulf through phagocytosis and are finally digested in lysosomal of macrophages as depicted in Fig. 1. The marked increase in bioavailability of anticancer drugs and drugs entrapped in liposome provide an indirect reflection of the success rate of inhalant therapy [6].

Drug delivery to lungs through inhalation has several advantages:

- High bioavailability of drugs can be achieved in lungs because of limited intracellular and extracellular drug - metabolizing enzyme activities.

- Inhalation therapy shows rapid onset of action due to the availability of huge pulmonary surface area and profuse vasculature.

- Localized therapy reduces the chances of non-reversible tissue damage caused by cytotoxicity of the drug.

- Localization of the drug assists in the reduction of the dose and chances of drug degradation.

- Inhalation therapy encourages self-administration and thereby improves patient compliance.

- Harmonic interaction of formulation factors and design of device enhance solute permeability due to a reduction in particle size and use of novel technologies [2,7].

In physiological conditions, mucus, a viscoelastic gel, is secreted to protect cellular surfaces and maintain water balance. These mucus layers act as a filter to remove pathogens. Therefore, mucus production by epithelial cells is a physical barrier and rate-limiting step for drug targeting. Adhesion interactions usually occur between mucus and drug particles through electrostatic, hydrophobic, and hydrogen bonding [8].

For an effective drug targeting in lung, various physiological challenges need to be assessed. Those challenges include ability to target the drug at the specific area or cells, penetrability of drugs through airway mucosa and escaping mucociliary clearance, transportability of the drug across epithelial cells into bloodstream for systemic exposure, with the ability to overcome the hindrance of penetration and inactivation by bacterial biofilm in cases of infections, and minimal interactions between host protein and drug molecule [9]. 


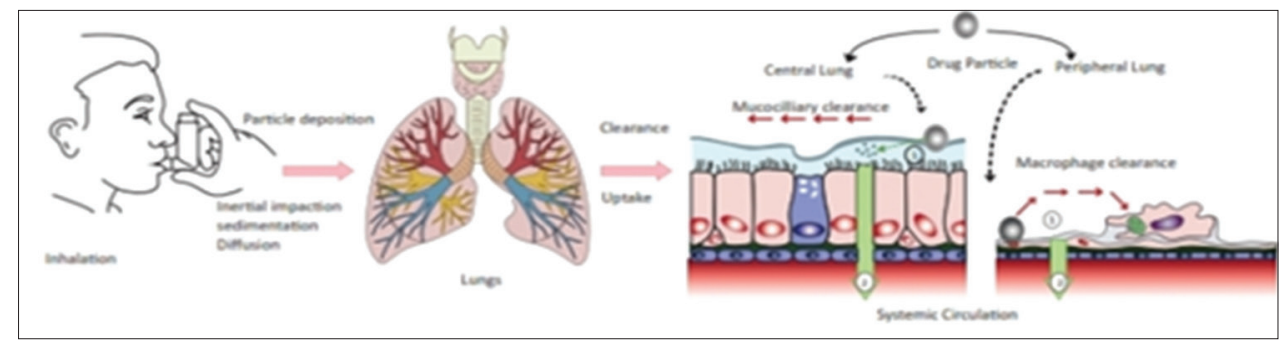

Fig. 1: Mechanism of particles deposition in lungs

It has been observed that more than 10-fold increases in mucus production occur in chronic bronchitis patients compared to healthy subjects. It is necessary to manipulate the physicochemical properties of drugs such as surface charges or hydrophobicity to avoid the entrapment of drugs in the mucus and increase the penetration of drugs across the mucus layers [10]. The bioavailability of the drug in lungs depends on factors such as aqueous solubility, dissolution rate, efflux of drugs, and drug clearance by alveolar macrophages. Most insoluble particles, with an aerodynamic diameter larger than $6 \mu \mathrm{m}$, are eliminated by mucociliary clearance. Hence, nano-sized particles can travel faster to reach bronchial epithelial region and escape the action. The major challenges lie in the formulation of drugs with poor aqueous solubility and poor cytosolic penetration. Poor aqueous solubility may cause local irritation and inflammation in the airways whereas poor penetration prevents the entrance of the drug to intracellular pathogens.

\section{DEPOSITION OF PARTICLE TO THE RESPIRATORY TRACT}

The three main mechanisms of particles deposition in healthy lungs are inertial impaction, gravitational sedimentation, and Brownian diffusion [8,11,12]. Deposition can also occur by electrostatic precipitation and by interception of elongated particles. Particle size, velocity, and settling time (Table 1) play an important role in lung deposition.

\section{Inertial impaction}

The process of deposition by impaction depends on air velocity, mass and the aerodynamic diameter of the particle. Although the airflow changes in the bifurcated airways, the suspended particles tend to travel in their original pathways and deposits on the surface due to impaction. Particles as small as $2 \mu \mathrm{m}$ and as large as $5 \mu \mathrm{m}$ in diameter are deposited primarily by inertial impaction. The preferred sites of deposition by inertial impaction are at the bronchial region, especially at the upper respiratory tract. The inertial impaction is expressed by Stoke's number.

Stk $=\left(\rho_{\mathrm{p}} \mathrm{d}_{\mathrm{p}}{ }^{2} \mathrm{u}\right) / 18 \mu \mathrm{d} \ldots \ldots$

Where Stk $=$ stokes number, $d_{p}$ is the particle diameter, and $\rho_{p}$ is the particulate density, $u$ is the linear velocity and $\mu$ is the dynamic viscosity of the carrier gas, and $d$ is a characteristic length which is equal to the diameter of the airspace. The significance of stokes' number lies in the fact that the higher the number, the more likeliness that particle will deposit by inertial impaction at the respiratory tract [8]. Therefore, particles size, the linear velocity of the inhaled air and particulate density is the major factors that determine respiratory tract deposition.

\section{Gravitational sedimentation}

Settling of particles in the smaller airways of the bronchioles and alveoli, under the action of gravity is the sole mechanism of gravitational sedimentation. Rate of sedimentation in these areas depends on terminal settling velocity of the particles. Particles achieve the terminal settling velocity when gravitational force and the resistive forces of the air become equal. Particles with a diameter ranging from 0.5 to $5 \mu \mathrm{m}$ are preferred for gravitational sedimentation at the upper respiratory tract, small airways, and alveoli.
Table 1: Deposition of particles to the respiratory tract

\begin{tabular}{ll}
\hline Particle size & Site of deposition in lungs \\
\hline $1-5 \mu \mathrm{m}$ & $\begin{array}{l}\text { Deposits in the lung periphery and penetrate } \\
\text { lung periphery }\end{array}$ \\
$5-10 \mu \mathrm{m}$ & $\begin{array}{l}\text { Particles deposit in the large bronchi } \\
\text { oropharyngeal region }\end{array}$ \\
$10-15 \mu \mathrm{m}$ & $\begin{array}{l}\text { Deposit in the upper airways } \\
\text { Deposit and removed from mostly in the nose } \\
\text { and mouth }\end{array}$ \\
\hline
\end{tabular}

The terminal settling velocity $\left(\mathrm{V}_{\mathrm{s}}\right)$ for a spherical sphere is expressed by the following equation:

$\mathrm{V}_{\mathrm{s}}=\left(\rho_{\mathrm{p}} \mathrm{d}_{\mathrm{p}}{ }^{2} \mathrm{~g}\right) / 18 \mu \ldots \ldots$

Where $\mathrm{g}$ is gravitational acceleration. Therefore, settling velocity increases with increasing particle size and density, and the deposition due to settling increases residence time.

\section{Brownian diffusion}

Collisions of the particles with gas molecules initiate random wiggling motion and result in deposition of particles by Brownian diffusion process. Brownian diffusion is inversely proportional to particle size and mostly occurs for particles of $<0.5 \mu \mathrm{m}$ in diameter. Deposition by Brownian diffusion mostly seen in the acinar region of the lung $\left(d_{p}<0.01 \mu \mathrm{m}\right)$ and in the nose, mouth, and pharyngeal airway.

\section{FACTORS AFFECTING PARTICLE DEPOSITION IN THE DISEASED LUNG}

Deposition of particles in lungs alters tremendously due to bronchial obstruction, alteration in alveolar dimensions, and changes in breathing patterns. Obstruction of airways during bronchitis, cystic fibrosis, lung cancer, and emphysema reduces exposure to aerosolized stream and thereby, deposition in the alveolar spaces is affected. This is due to narrowing of the airways by inflammation, mucus secretion, or bronchial constriction [6]. The physicochemical properties of the composition, particle size and suitability for toxicological qualification determine the effectiveness of the formulation, whereas the design and performance of inhaler affect the drug deposition.

Depending on the above fact of particle deposition, to design an effective inhaler the following parameters as mentioned in Table 2 should be considered.

\section{CURRENT INHALER DEVICES}

Three clinically successful and competent pulmonary inhalation devices currently available are nebulizers, pressurized metered-dose inhaler (pMDIs), dry powder inhalers (DPIs), and soft mist inhalers.

\section{NEBULIZER}

A nebulizer is a means for intending a medication into the lungs through nose in the form of fine mist. A nebulizer assists a physical change of medication from a liquid into a mist for easy inhalation of the drug 
Table 2: Consideration of essential parameters for the designing of an effective inhaler

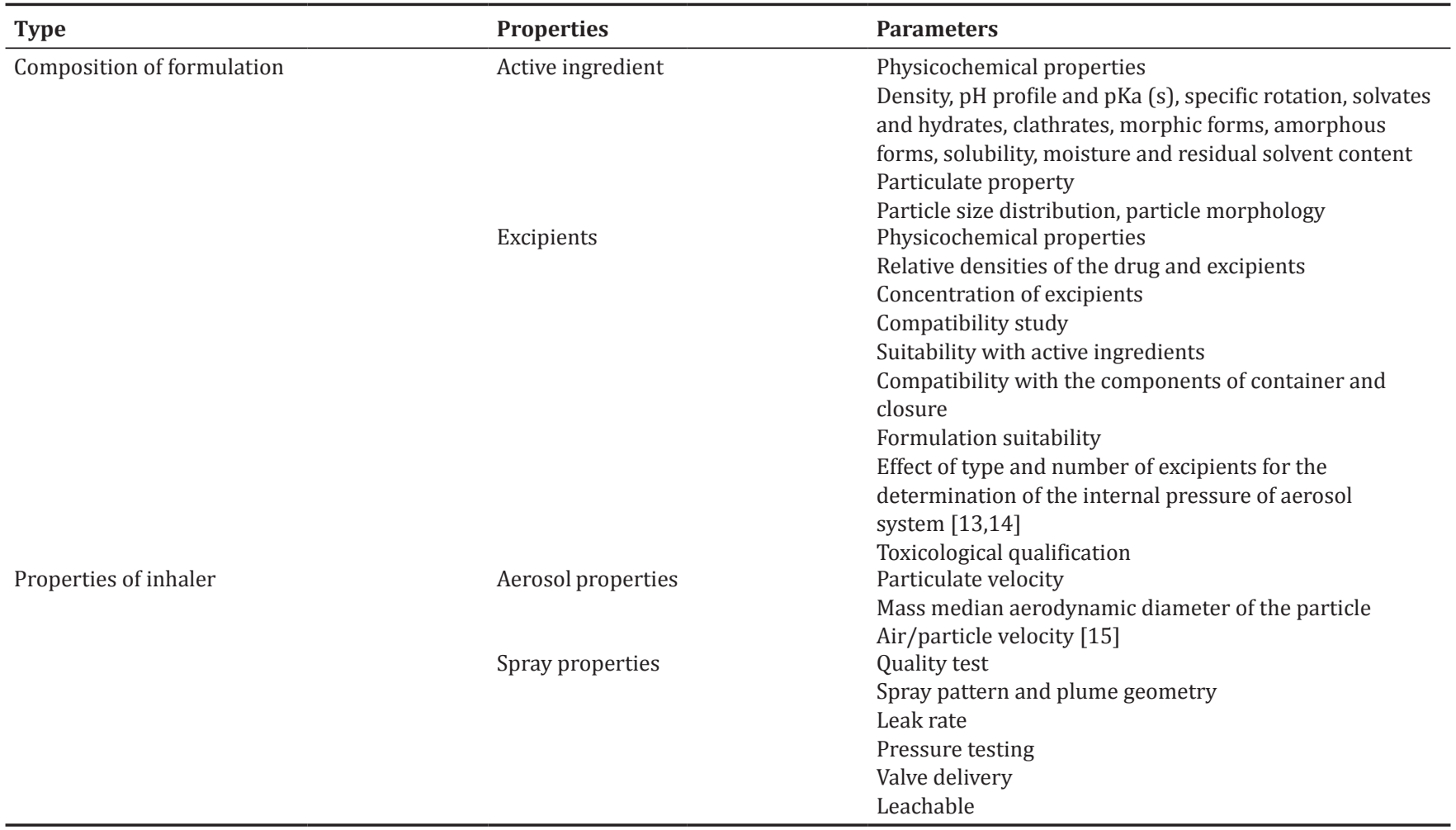

Table 3: Examples of nebulizers with novel technologies

\begin{tabular}{llll}
\hline Generic drug & Nebulizer brand & Type & References \\
\hline Aztreonam $\left(\right.$ Cayston $\left.^{\circledR}\right)$ & Altera $^{\mathrm{TM}}$ Nebulizer System & Vibrating membrane technology \\
${\text { Tobramycin }\left(\mathrm{TOBI}^{\circledR}\right)}_{\text {Pulmozyme }^{\circledR}}$ & Pari LC $^{\circledR}$, Sidestream plus & Breath-enhanced Jet nebulizer \\
\hline
\end{tabular}

Table 4: Examples of pMDI with novel technologies

\begin{tabular}{|c|c|c|c|}
\hline Generic drug & pMDI (brand name) & Type & References \\
\hline Ipratropium bromide HFA & Atrovent ${ }^{\circledR} \mathrm{HFA}$ & Inhalation aerosol & {$[27]$} \\
\hline Pirbuterol acetate & Maxair $^{\mathrm{TM}}$ Autohaler ${ }^{\mathrm{TM}}$ & Inhalation aerosol & [19] \\
\hline Fluticasone propionate & Flovent ${ }^{\circledR}$ HFA & Inhalation aerosol & {$[31,37]$} \\
\hline Budesonide and formoterol fumarate dihydrate & Symbicort $^{\circledR}$ & Inhalation aerosol & [5] \\
\hline
\end{tabular}

pMDI: Pressurized metered-dose inhaler, HFA: Hydrofluoroalkane

Table 5: Properties of various types of multiple dose DPI

\begin{tabular}{|c|c|c|c|}
\hline Properties & Flexhaler & Twisthaler & Diskus \\
\hline Dose container & Reservoir & Reservoir & Blister strip \\
\hline Number of doses & $60-120$ & 30 & 60 \\
\hline Mechanism & $\begin{array}{l}\text { Should be primed by holding it upright } \\
\text { and twist before use }\end{array}$ & $\begin{array}{l}\text { Priming before use is not } \\
\text { required. }\end{array}$ & $\begin{array}{l}\text { Puncturing the wrapped blister on a } \\
\text { foil strip by Sliding the dose-release } \\
\text { lever }\end{array}$ \\
\hline Dose Indicator & $\begin{array}{l}\text { Each incident of loading a dose the } \\
\text { indicator counts down, it moves at } \\
\text { intervals of five or so doses and marks } \\
\text { at intervals of } 10 \text { doses, with some } \\
\text { indication. When it displays "0," it must } \\
\text { be thrown away }\end{array}$ & $\begin{array}{l}\text { Display of " } 01 \text { " in the dose } \\
\text { indicator indicates the last dose } \\
\text { of medicine and subsequent } \\
\text { refilling }\end{array}$ & $\begin{array}{l}\text { Change of number color to red in the } \\
\text { dose display indicates the presence of } \\
\text { last five doses [19] }\end{array}$ \\
\hline
\end{tabular}

into the lungs. Patient coordination between inhalation and actuation is not required. Depending on the model and the make, nebulizers generate 1-5 $\mu \mathrm{m}$ droplets [16,17]. Most liposomal formulations for inhalation have been developed for use in nebulizers. Both jet and mesh nebulization processes expose liposomal formulation to shear in the air-liquid interface which disrupts liposomal bilayers, resulting in 
Table 6: Examples of DPI

\begin{tabular}{lll}
\hline Generic drug & DPI brand & Type \\
\hline Formoterol & Aerolizer $^{\circledR}$ & Single dose DPI \\
Tiotropium bromide & HandiHaler $^{\circledR}$ & Single dose DPI \\
Zanamivir & Diskhaler $^{\circledR}$ & Multiple unit-dose DPIs \\
Budesonide & Flexhaler ${ }^{\circledR}$ & Multiple-dose DPIs \\
Salmeterol, fluticasone and its combination & Diskus ${ }^{\circledR}$ & Multiple-dose DPIs \\
Beclomethasone dipropionate anhydrous and formoterol & NEXThaler & Single dose DPI \\
fumarate dihydrate & & {$[19]$} \\
\hline
\end{tabular}

DPI: Dry powder inhaler

Table 7: Example of marketed Soft Mist Inhaler

\begin{tabular}{llll}
\hline Generic drug & Soft Mist inhaler (brand name) & Type & References \\
\hline Ipratropium bromide and fenoterol hydrobromide & Respimat $^{\circledR}$ & Soft Mist Inhaler & [9] \\
\hline
\end{tabular}

vesicle fusion with either a corresponding increase in vesicle size or fragmentation with its associated reduction in vesicle size [18].

\section{Advantages}

- It can aerosolize mixtures of drugs for combination therapy.

- Large doses can be easily administered.

- It is easy to administer, and effective with patients distressed breathing pattern.

- Least patient coordination with the inhalation technique makes it useful for very young, very old, and debilitated distressed patients.

- Modification of drug concentrations and dose can be done depending on patients need [19].

\section{Disadvantages}

- Treatment times can vary depending on the severity of the disease.

- Transportability is less as equipment may be large and requires a power source to operate.

- It shows variations in performance among different types, brands, and models.

- To prevent possible contamination cleaning after each application is required.

\section{Small volume nebulizer (SVN)}

The SVN uses compressed air, oxygen, driven by a compressor or electrically powered device to convert liquid drug solutions or suspensions into an aerosol. There are three different types of SVN are available. Various types of nebulizers already in market with novel approaches are listed in Table 3.

\section{Types of SVN}

\section{Jet nebulizers}

Certain antibiotics, mucolytic, and liposomal formulations are effectively delivered through jet nebulizers. Jet nebulizers work on Venturi's principle. Their operation requires compressed air or oxygen gas and tubing. In jet nebulizer, the air is subjected to pass through a narrow capillary, and subsequent reduction in fluid pressure takes place. The aerosolized solution pass through the gas stream. The aerosol stream strikes a baffle to produce smaller droplets which are sheared into a liquid film. This film is unstable and further breaks into droplets $[20,21]$. They are the least expensive kind of nebulizer. The recent development of smart jet nebulizer-AKITA ${ }^{\circledR}$ JET (Vectura) helps to achieve targeted inhalation therapy. It is a breath-actuated system and operates at a low inspirational flow.

\section{Ultrasonic nebulizers}

In ultrasonic nebulizers, electrical energy is converted to highfrequency (1-3 MHz) vibrations with the help of a transducer. Sound waves are generated due to the vibration of piezoelectric crystals at high frequency. These vibrations at the surface of the solution help to create a standing wave that generates aerosol [22]. They are of two types large volume and small volume ultrasonic nebulizer. Small volume ultrasonic nebulizers are mostly used for inhalation therapy.

\section{Mesh nebulizers}

Mesh nebulizers are battery operated, portable, and silent nebulizers. They are two types (a) vibrating mesh nebulizer and (b) static mesh nebulizer.

The basic principle of mesh nebulizer is the vibration of a piezo element at around $\sim 128 \mathrm{KHz}$. This vibration leads to the movement of liquid formulations through a fine mesh to generate aerosolized stream. The particle size of the aerosolized stream is determined by the diameter of the mesh or aperture. Mesh nebulizers are reported to be very efficient and result in minimal residual volume $(0.1-0.5 \mathrm{~mL})$.

The latest generation I Neb Adaptive aerosol delivery system is a type of vibrating mesh nebulizer which analyses patients breathing control pattern, has a unique metering chamber of precise dose delivery [23].

FOX $^{\circledR}$, battery-operated hand-held nebulizer system based on aerosol bolus technology is an extension of vibrating mesh nebulizer of high performance.

The Micro air ${ }^{\circledR}$ NE-U22V is the marketed static mesh nebulizer. It can nebulize aqueous solutions and suspensions of the drug. Droplets generated by this mesh nebulizer have a size of $3 \mu \mathrm{m}$ [24]. Marketed vibrating mesh nebulizers such as Pari eFlow ${ }^{\circledR}$ rapid and Omron U22 have a mesh plate. When the plate vibrates due to the action of the piezoelectric element, it breaks the liquid into very fine droplets [25]. The aerosol, thus, produced at a moderate velocity inside the nebulizer, leaves from the valve as a standing cloud at a low velocity. In Pari eFlow $^{\circledR}$ system an inspiratory and expiratory valve mechanism during inhalation minimizes leakage of aerosol and can be useful with a maximum volume of $6 \mathrm{~mL}$.

\section{Breathe actuated nebulizer}

The AeroEclipse ${ }^{\circledR}$ II nebulizer aerosolizes the solution of the drug as per patient's inspiratory effort. It is clinically proven that it can deliver a high respirable dose to its optimal particle size to the affected areas of lungs. In this technology, the drug can be available during inhalation and exhalation phase, and it depends on inhalation: Exhalation (I: E) ratio. This property minimizes loss of drug and economic utilization of drug. Its one-way valve mechanism provides protection against harmful viruses [26].

\section{Excipient used in nebulization}

The various excipient used in nebulization

- Isotonic solvent system - sodium chloride is widely used to adjust the osmolality of solutions to approximately $300 \mathrm{mosmol} / \mathrm{l}$. Particulate 
and alcohol-based Proliposomes can readily be converted to isotonic liposomes formulations with the help of jet or mesh nebulizer.

- $\quad$ pH adjustment system - hydrochloric acid, sodium hydroxide, citric acid, and phosphate salts are commonly used to adjust the $\mathrm{pH}$ of the solution.

- Surfactants - surfactants such as polysorbates and sorbitan are generally present to aid dispersion or dissolution of the drugs in the solvent system.

- Cosolvent - cosolvent such as ethanol may be used only in small amounts as it may irritate pulmonary epithelium.

- Preservative - methylparaben and propylparaben are used as preservative [27-29].

\section{${ }_{\mathrm{p}} \mathrm{MDI}$}

The most popular inhalers used in the treatment of local respiratory diseases are pMDI [32]. The conventional pMDI consists of a canister, metering valve, actuator and a mouthpiece. MDIs contain a solution or suspension of drug dispersed in a propellant that on actuation delivers an aerosol bolus. It is an inexpensive and pocket-sized device, but, has a greater potential for misuse and are generally appropriate for molecules that are potent at low doses [33]. A few scientists have found some success formulating liposomes in MDIs or using MDIs that facilitate the spontaneous formation of liposomes once the aerosol deposits in an aqueous environment as would occur in the airways [34]. The basic components of a pMDI system are described as below:

- Canister - canister is made of inert materials of plastic, stainless steel, glass, and aluminum. The canister should be able to withstand the high pressures of the propellant gas equilibrium with its liquid state.

- Metering valve - metering valve is made to deliver a fixed amount of aerosol $(20-100 \mu \mathrm{L})$ of potent medication per actuation. It is either crimped onto the container or sealed with elastomeric valves and thus preventing drug loss due to leakage.

- Actuator - actuator is made to deliver the aerosol product in its proper and desired form. It includes a spray nozzle (actuator orifice) and an expansion chamber. In the expansion chamber or "boot," the released propellant from the metering chamber expands and partially volatizes due to the decrease in pressure. The orifice helps to aid in producing required type of discharge in the form of spray, foam or solid stream. Each boot is unique to a specific pMDI with a specific drug.

- Propellants - liquefied compressed gases in which the drug is dissolved or Suspended. It is the key component for developing pressure within the container which helps to expel the product on the opening of valve. A blend of fluorocarbons propellants is generally used to produce a desired vapor pressure inside the canister [32,35].

\section{Advantages}

- Portable, light, and compact assembly of pMDI are easily transportable.

- Multiple doses can be dispensed conveniently in a single assembly.

- A dose can be removed without contamination of the remaining product, sterility can be maintained throughout its use.

- As medication is delivered directly to the affected area, it reduces dose and treatment time.

- It minimizes number of administration errors with reproducibility of the emitted doses [30].

\section{Disadvantages}

- Presence of chlorofluorocarbon (CFCs) or hydro fluoro alkane (HFAs) lead to produce extra fine particles of the emitted dose, this may cause a high proportion of drug deposition in the mouth and oropharynx regions, increases the chances of local and systemic side effects due to rapid absorption.

- It is difficult to determine the dose remaining in the canister without dose counter and a phenomenon called tail-off, i.e. release of aerosol plume with little or no drug, can happen beyond the labeled number of actuation.

- To achieve success in delivery patient's proper inhalation pattern for "extrafine" aerosols (particle size in the range of $1 \mu \mathrm{m}$ ), breath-hold technique is required.
- $\quad$ Some patients show a reaction to propellants.

- Improper inhalation technique leads to high oropharyngeal deposition and thereby medication errors.

\section{Types of pMDI}

\section{Conventional $p M D I$}

In the conventional pMDI system, the medication comprises only $1-2 \%$ of the mixture is made to suspend or dissolve in the propellant/excipient mixture constituting $80 \%$ of the mixture. To prevent aggregation of the drug particles and to ensure lubrication of the metering valve, a surfaceactive agent is occasionally used. Addition of surfactants ensures well distribution of the drug in the formulation. In the metering valve, the volume varies from 25 to $100 \mu \mathrm{L}$ and provides $50 \mu \mathrm{g}-5 \mathrm{mg}$ of drug per actuation, depending on the drug formulation. The two types of propellants used with pMDI are CFCs and HFAs [36].

\section{Breath-actuated pMDI}

The Autohaler ${ }^{\mathrm{TM}}$ (Graceway Pharmaceuticals, Bristol, TN) uses a breath actuate nozzle, which helps to eliminate the need for hand-held coordination during drug administration by inhalation and provides an automatic response to the patient's inspiratory effort [36-38]. It contains a pressurized canister with a spring-loaded mechanism to trigger the flow automatically during inhalation. It can dispense the aerosol even at a medium to low inspiratory flow rate.

\section{Excipient used in MDIs}

In an MDI, the drug is either suspended or dissolved in a propellant mixture $[27,34,39]$. The vapor pressure of the liquefied propellant serves as the source of energy and expels the formulation from the valve in the form of rapidly evaporating droplets. The liquefied propellant serves as a dispersion medium for the drug and another excipient also.

- Propellants: CFC-based MDIs generally contains a mixture of a liquefied low boiling-point propellant like CFC 12 (dichlorodifluoromethane) and a liquefied higher boiling-point propellant such as CFC 11 (trichlorofluoromethane) or CFC114 (dichlorotetrafluoromethane). The international communities environmental protection agency, American FDA (USFDA), and consumer products safety commission agreed to replace CFC propellants in 1979 and later under the agreement of the United Nations Montreal Protocol the use of CFC is restricted worldwide from the $21^{\text {st }}$ century. HFAs replaces the use of CFC propellants. HFA 134a (1,1,1,2-tetrafluoroethane) and HFA 227 (heptafluoropropane) are now considered as established excipient. The disadvantages associated with HFAs are, that commonly used surface-active agents are almost totally insoluble in it. Hence, physical stabilization of drug particles in suspension is inadequate.

- Surface active agents: The surface active agents commonly used to aid dispersion of suspended drug particles or dissolution of a partially soluble drug and to lubricate the metering mechanism are Sorbitan trioleate (SPAN 85), oleic acid, and soya lecithin, at a concentration between $0.1 \%$ and $2.0 \%(\mathrm{w} / \mathrm{w})$.

- Other additives: Flavors, sweeteners, antioxidants, and chelating agents can be added for increasing palatability and enhancement of stability of the formulation.

The various types currently marketed pMDI are listed in Table 4.

\section{DPI}

An active therapeutic agent in powder form can be delivered through pulmonary route effectively by means of DPI for local and systemic effect. DPIs are portable, inspiratory flow-driven inhalers devices. In the year 2008, USFDA had put an end to selling of MDI with CFC. As an alternative to pMDI, DPIs are developed. They are free of propellant and are breath-actuated. In DPIs, fine drug particles of size less than $5 \mu \mathrm{m}$ are blended with the suitable large carrier (e.g., lactose). Presence of carrier materials not only improves the flow properties but also provide dose uniformity of potent drug [40]. The drug particles disperse in the form of microdispersion from the device during inspiration. Powder 
deagglomeration and aero ionization of the formulation occurs through patients own inspiratory effort. Dry powder devices which operate at a low inspiratory flow rate, e.g.: Diskhaler and Turbohaler are clinically desirable for children and adults with decreased lung function either because of age or disease [41].

\section{Industrial advantages}

- Devices are free of propellant.

- $\quad$ Ease delivery of poorly water-soluble drug, protein and peptide drugs can be achieved in stable powder form.

- Encapsulation of the drug with carriers promotes stability of the drug.

- An extended release profile with improved penetrability can be achieved with dried liposomal inhalation [42].

\section{Clinical advantages}

- DPIs are generally small and portable.

- Presence of inert carrier and propellant-free system improves tolerability and reduction of toxicity among patients.

- DPIs are suitably designed in built-in dose container, make them easy to use.

- As they are breathing actuated device, there is less need for patient coordination, so they are easy to use.

- Preparation and administration time are short.

- They possess less potential for formulation problems.

Disadvantages

- Effectivity and success of drug delivery are largely dependent on patient's inspiratory flow rate and pulmonary condition.

- Oropharyngeal impaction is high.

- Care should be taken on exposure of powder to atmospheric humidity and exhaled humidity into mouthpiece as it may affect the deagglomeration process of conversion into finer particles.

- It provides less protection from environmental effects and patient abuse.

- DPIs are comparatively expensive than pMDIs.

- This system of pulmonary delivery is suitable for a limited range of drugs.

\section{Types of DPIs}

Based on the design of dose containers, DPIs can be classified into three categories, i.e., single-dose DPIs, multiple unit-dose DPIs, and multipledose DPIs [19,43].

\section{Single dose DPIs}

In single-dose DPIs powder drug is made to evacuate from a punctured capsule. The capsule in the drug holder is pierced, and air enters the device for dispersion into fine stream of particles during inhalation. The main drawback of single-dose DPIs is the time needed to load a dose for each use and patients should be instructed not to eat the capsules.

\section{Multiple unit-dose DPIs}

The Diskhaler is an example of multiple unit-dose DPI. It has a refill disk that contains 4 or 8 unit-dose blisters. On actuation, each blister is punctured mechanically inside the device. With an inspiratory flow rate $>60 \mathrm{l} / \mathrm{min}$ an adequate drug deposition into the lungs can be achieved. It does not have a dose counter, so doses must be tracked manually. Visual inspection confirms the use of all packets. The disk is disposed of when all the doses have been used.

\section{Multiple-dose DPIs}

Multiple-dose DPIs come with integrated mechanical devices. An account of the number of doses remaining in the inhaler can be obtained. The devices give an alert display to the patient for new procurement. They are three types Flexhaler, Twisthaler, and Diskus. The differences in the types of multiple dose DPIs are illustrated in Table 5.

\section{Excipient used in DPIs}

Particle-size distribution affects drug's deposition in the respiratory tract. Hence, in the formulation of a DPI system, four parameters play a key role, i.e., a dose-metering mechanism, an aerosolization mechanism, a deaggregation mechanism, and an adaptor to direct the aerosol into the mouth. In general, very fine particles exhibit stronger cohesive forces, resulting in poor flow properties. Hence, careful selection of blending process with the excipient is needed [44-46]

The commonly used excipient are listed as below

- $\quad$ Sugars - lactose, glucose, mannitol, and Trehalose are used as carriers.

- Hydrophobic additives - to protect the drug from moisture, magnesium stearate is used.

- Lipids - dipalmitoylphosphatidylcholine, distearoyl phosphatidylcholine, dimyristoyl phosphatidylcholine, and cholesterol are used for liposomal drug delivery and coating of the particles.

- Amino acids - leucine and trileucine are used to improve the aerosol efficiency and targeting at lungs.

- Surfactants - to produce light and porous particles poloxamer is used.

- Absorption enhancers - hydroxypropylated - beta-cyclodextrin, natural gamma-cyclodextrin, bile salts, chitosan, and trimethylchitosan are used for absorption enhancers for proteins and peptides.

- Biodegradable polymers are also used for sustained release formulations.

The currently marketed DPIs are listed in Table 6.

\section{SOFT MIST INHALER}

The Respimat ${ }^{\circledR}$ (Boehringer Ingelheim Pharmaceuticals, Ridgefield, CT) system is a propellant-free Soft Mist inhaler as listed in Table 7. It utilizes a tensioned spring to generate the soft aerosol plume. The device is free from propellant; hence, shaking of the canister is not required. It represents a novel approach to the inhalation therapy and overcomes few limitations of pMDI, DPI, and nebulizers. The Respimat ${ }^{\circledR}$ can produce droplets of diameter between 1 and $5.8 \mu \mathrm{m}$. The droplet size in this range helps to avoid loss of small droplets during the subsequent exhalation and facilitates efficient lung deposition $[50,51]$

\section{Advantages}

- They are small and portable.

- Supply of power is not required for its operation.

- Device is propellant-free and spacer free.

- The soft aerosol plume reaches the pulmonary tissue efficiently, so medication loss due to oropharyngeal deposition can be overcome.

- It has a dose indicator and gets locked when medications are exhausted [Ibrahim].

- It is inspiratory flow rate independent.

\section{Disadvantages}

- They are comparatively expensive.

- It is not breathing controlled device.

- It requires filling of capsule followed by rotation of the device before inhalation, so handling becomes difficult especially for elderly patients.

\section{CHALLENGES IN INHALER PERFORMANCE AND DRUG DELIVERY}

\section{Nebulizer}

There is wide availability of nebulizers in the market. However, the performance of nebulizers varies from manufacturer to manufacturer.

Drug delivery is largely dependent on the rate of nebulization and greatly affected by particle size. The physicochemical properties of the formulation such as viscosity, ionic strength, osmolality, $\mathrm{pH}$, and surface tension affect the performance of nebulizer. Inhalation through nebulization may induce bronchoconstriction, coughing and irritation of the lung mucosa at low $\mathrm{pH}$, or at hyper- or hypo-osmolality of the formulation. High drug concentrations can affect the drug output with some nebulizers, e.g. colomycin at concentrations $>75 \mathrm{mg} / \mathrm{ml}$ foams in all nebulizers, making aerosolization of the drug very inefficient [36]. 
pMDI

The effectiveness and efficiency of an MDI depend on a patient's breathing pattern, inspiratory flow rate and hand-mouth coordination. For an effective delivery of drug and prevention of oropharyngeal loss through pMDI, it requires spacers or holding chambers or valve holding chambers (VHC) in clinical practice. Use of improper technique can decrease drug delivery eventually loss of dose. The reasons for decreased drug delivery through pMDI can be due to electrostatic charge, inhalation before actuation, multiple actuations into the device, or delay between actuation and inhaling the dose. Lack of a proper mask fit, a spacer volume greater than tidal volume is considered problematic for children [19].

\section{DPI}

The delivery efficiency of a DPI depends on the intrinsic resistance of patients breathing pattern, exposure of powder material to moisture and the particle size.

Intrinsic resistance - as they are inspiratory flow-driven inhalers, patient's inspiratory effort plays a crucial role in deaggregation of powder into finer particles. This type of delivery may not be suitable for very young population and patients suffering from chronic obstructive pulmonary disease as they may not be able to generate an adequate inspiratory flow.

Exposure to humidity - the flow properties of aerosolized powders in a DPI system are affected by humidity and moisture. This can cause powder clogging and problem in fine-particle development during inhalation, so they must be kept dry.

Particle engineering - most important factor involved in evaluating DPI performance is the engineering of particle size. In a review, Staniforth explained the Pascal system. This is an example of improved DPI system with carrier formulation technology. It uses a novel single step process called as Corrasion. In this process, mixing and surface modifications of mixtures of $\alpha$ Lactose monohydrate and amino acid L-leucine take place simultaneously, and thereby produces a powder formulation that delivers accurate, uniform and efficient doses of the drug [52].

Medspray's inhalers and sprays are the next generation inhalers, under clinical study, aims to generate aerosols with a narrow distributed particle size of micro and nanotechnology. It is designed to aim for more efficacious and simple aerosol delivery of drugs to the specific targeted sites with improved patient compliance.

\section{IMPORTANCE OF PATIENT'S BREATHING PATTERN IN INHALATION THERAPY}

The design of inhalation system and patient respiratory effort play a key role to maximize drug uptake into lungs. Incorrect inhaler technique and poor device technology lead to inhaler misuse. Age and illness of the patient are the determinants of affectivity of inhalation system. The variation in deposition varies from $20 \%$ to $95 \%$ with a standard inhalation device. Long period of treatment increases the chances of patient's noncompliance and dose-related toxicity. Hence, breathing pattern should be controlled to ensure adequate, effective and quick therapy. Medical personnel should train the patient at the time of initiation of therapy. For the aerosol system patients are advised to take an initial deep breath and holding of breath for $10 \mathrm{~s}$ to allow the settlement of the particles in the deep pulmonary region. In case of pMDIs addition of spacer can help in coordination between actuation of the device and patient inhalation by slowing the velocity and reduction in particle size. Similarly, a VHC for pMDI system opens easily with patient's inspiratory effort through one-way opening of the valve. However, improper techniques, multiple actuations, inhaling before actuating the pMDI system may decrease drug delivery through spacer and VHC. Recent development of AKITA technology aims in individualization and controlled inhalation with popular nebulizers using a smart card to ensure consistent and optimal dosing [53].

\section{CONCLUSION}

Pulmonary administration through inhalation technique has become an attractive route of drug delivery to treat chronic and severe disease conditions with target specificity, economic utilization of drug and toxicity-limiting point of view. It also avoids problems associated with intravenous delivery. To maximize drug concentration at the site of action and to improve the drug efficacy, the therapeutic agent is made to localize in the airways during the inhalation therapy. Hence, the particle diameter and its aerodynamic velocity play a crucial role. It has been reported that targeting drug through nanoparticles reduces chances of resistance of antibiotics [54-57]. To achieve success in inhalation therapy through a harmonic interaction with breathing and inhaler mechanism patient should be trained properly. Recent advancement in pulmonary drug delivery has been achieved by introduction of new particle engineering technologies through spray drying, freeze drying, spray freeze drying, use of biodegradable polymers and binding of drug formulations with specific ligands for effective site-specific lung targeting [58-60]. The structure and design of inhaler play a major role on the aerosol deposition to the lungs. An ideal inhaler should deliver precise and consistent doses to the targeted region of the lungs keeping the stability of the formulation throughout its shelf-life. In the development of new inhalation medications, consideration must be given to the formulation ingredients to ensure chemically stability, non-irritability with improved bioavailability of the formulation. It should also be compatible with a suitable metering system to produce a convenient device that is comfortable and easy to use by the patient. Hence, the inhaler drug combination should serve as a one in all, compact, single medication for effective use, of which the in vitro performance and in vivo efficacy must be demonstrated.

\section{ACKNOWLEDGMENTS}

Authors are grateful to Mr. A.N Noufel from Honeycomb Creative Support (P) Ltd., Bengaluru, India, for providing the support for enhancement of quality of the pictures used in this review. We sincerely express our respect and gratitude to Management, Principal, Dr. Amit $\mathrm{Kr}$ Das and Dr. Kuntal Das of Krupanidhi College of Pharmacy, Bengaluru, for providing all necessary support and facility to complete this review work.

\section{AUTHOR CONTRIBUTIONS}

Both the authors were equally involved in the drafting, gathering information and design of framework of the manuscript.

\section{CONFLICT OF INTEREST}

The authors confirm that this article content has no conflict of interest.

\section{REFERENCES}

1. Daman Z, Gilani K, Rouholamini Najafabadi A, Eftekhari HR, Barghi MA. Formulation of inhalable lipid-based salbutamol sulfate microparticles by spray drying technique. Daru 2014;22:50.

2. Zhang J, Wu L, Chan HK, Watanabe W. Formation, characterization, and fate of inhaled drug nanoparticles. Adv Drug Deliv Rev 2011;63:441-55.

3. Heijerman H, Westerman E, Conway S, Touw D. Inhaled medication and inhalation devices for lung disease in patients with cystic fibrosis: A European consensus. J Cyst Fibros 2009;8:295-315.

4. Sanders M. Inhalation therapy: An historical review. Prim Care Respir J 2007; 16:71-81.

5. Kuzmov A, Minko T. Nanotechnology approaches for inhalation treatment of lung diseases. J Control Release 2015;219:500-18.

6. Schulz H, Brand P, Heyder J. Particle deposition in the respiratory tract. In: Gehr P, Heyder J, editors. Particle-Lung Interactions. New York: Dekker; 2000.

7. Jain KK. Drug Delivery Systems: An Overview (Methods in Molecular Biology). New York: Humana Press; 2008.

8. Darquenne C. Particle deposition in the lung. Encyclopedia of Respiratory Medicine. Amsterdam, UK: Elsevier Ltd.; 2006. p. 300-4.

9. Lee WH, Loo CY, Traini D, Young PM. Inhalation of nanoparticle- 
based drug for lung cancer treatment: Advantages and challenges. Asian J Pharm Sci 2015;10:481-9.

10. Todoroff J, Vanbever R. Fate of nanomedicines in the lungs. Curr Opin Colloid Interface Sci 2011;16:246-54.

11. Heyder J. Particle transport onto human airway surfaces. Eur J Respir Dis Suppl 1982;119:29-50

12. Hinds WC, Liu WC, Froines JR. Particle bounce in a personal cascade impactor: A field evaluation. Am Ind Hyg Assoc J 1985;46:517-23.

13. Ibrahim M, Verma R, Garcia-Contreras L. Inhalation drug delivery devices: Technology update. Med Devices (Auckl) 2015;8:131-9.

14. Ari A, Restrepo RD. American association for respiratory C. Aerosol delivery device selection for spontaneously breathing patients. RespiCare 2012;57:613-26.

15. Newman SP. Aerosol deposition considerations in inhalation therapy. Chest 1985;88:152S-60.

16. Hess D, Fisher D, Williams P, Pooler S, Kacmarek RM. Medication nebulizer performance. Effects of diluent volume, nebulizer flow, and nebulizer brand. Chest 1996;110:498-505.

17. Loffert DT, Ikle D, Nelson HS. A comparison of commercial jet nebulizers. Chest 1994;106:1788-92.

18. Niven RW, Schreier H. Nebulization of liposomes. I. Effects of lipid composition. Pharm Res 1990;7:1127-33.

19. Dean RH, Timothy R, Myers JL. A Guide to Aerosol Delivery Devices for Respiratory Therapy. Respirosonic; 2007.

20. Hess DR. Nebulizers: Principles and performance. RespirCare 2000;45:609-22

21. Jet AA. Ultrasonic and mesh nebulizers: An evaluation of nebulizers for better clinical outcomes. Eur J Pulmonol 2014;16:1-7.

22. Muchao FP, Silva FL. Advances in inhalation therapy in pediatrics. J Pediatr (Rio J) 2010;86:367-76

23. Dhand R. Intelligent nebulizers in the age of the internet: The I-neb adaptive aerosol delivery (AAD) system. J Aerosol Med Pulm Drug Deliv 2010;23:iii-v.

24. Vecellio L. The mesh nebuliser: A recent technical innovation for aerosol delivery. Breathe 2006;2:253-60

25. Available from: http://www.omnisurge.co.za/what-are-nebulizers-andhow-do-they-work. [Last accessed on 2017 May 03]

26. Cairo JM. Humidity and aerosol therapy In: Mosby's Respiratory care Equipment. 9 $^{\text {th }}$ ed. Missouri: Elseiver Inc.; 2014.

27. Pilcer G, Amighi K. Formulation strategy and use of excipients in pulmonary drug delivery. Int J Pharm 2010;392:1-9.

28. Newhouse MT, Hirst PH, Duddu SP, Walter YH, Tarara TE, Clark AR, et al. Inhalation of a dry powder tobramycin pulmo Sphere formulation in healthy volunteers. Chest 2003;124:360-6.

29. Nikolaizik WH, Jenni-Galovic B, Schoni MH. Bronchial constriction after nebulised tobramycin preparations and saline in patients with cystic fibrosis. Pneumology 1996;155:608-11.

30. Yang XF, Xu Y, Qu DS, Li HY. The influence of amino acids on aztreonam spray-dried powders for inhalation. Asian J Pharm Sci 2015;10:541-8.

31. d'Angelo I, Conte C, La Rotonda MI, Miro A, Quaglia F, Ungaro F, et al. Improving the efficacy of inhaled drugs in cystic fibrosis: Challenges and emerging drug delivery strategies. Adv Drug Deliv Rev 2014;75:92-111

32. Vaswani SK, Creticos PS. Metered dose inhaler: Past, present, and future. Ann Allergy Asthma Immunol 1998;80:11-9.

33. O’Donnell A, Swarnakar R, Yashina L, Nikolova P, Marinov R, Waghray P, et al. A Placebo Controlled Study of Liposomal Amikacin for Inhalation (ARIKACETM) Nebulized Once-Daily in the Treatment of Bronchiectasis Patients with Chronic Pseudomonas aeruginosa lung infection. Presented at: ERS Annual Conference Abstract 1361, Vienna, Austria, 13 September; 2009

34. Cipolla D, Gonda I, Chan HK. Liposomal formulations for inhalation. Ther Deliv 2013;4:1047-72.

35. Ibiapina CC, Cruz AA, Camargos PA. Hydrofluoroalkane as a propellant for pressurized metered-dose inhalers: History, pulmonary deposition, pharmacokinetics, efficacy and safety. J Pediatr (Rio J) 2004;80:441-6.

36. Labiris NR, Dolovich MB. Pulmonary drug delivery. Part II: The role of inhalant delivery devices and drug formulations in therapeutic effectiveness of aerosolized medications. $\mathrm{Br} \mathrm{J}$ Clin Pharmacol
2003;56:600-12

37. Newman SP. Principles of metered-dose inhaler design. Respir Care 2005;50:1177-90.

38. Newman SP, Weisz AW, Talaee N, Clarke SW. Improvement of drug delivery with a breath actuated pressurised aerosol for patients with poor inhaler technique. Thorax 1991;46:712-6.

39. Yadav N, Morris G, Harding SE, Ang S, Adams GG. Various noninjectable delivery systems for the treatment of diabetes mellitus. Endocr Metab Immune Disord Drug Targets 2009;9:1-3.

40. Dalby RN, Eicher J, Zierenberg B. Development of respimat ${ }^{\circledR}$ soft mist inhaler and its clinical utility in respiratory disorders. Med Devices 2011;4:145-55

41. Islam N, Gladki E. Dry powder inhalers (DPIs) - A review of device reliability and innovation. Int J Pharm 2008;360:1-1.

42. Hoppentocht M, Hagedoorn P, Frijlink HW, de Boer AH. Technological and practical challenges of dry powder inhalers and formulations. Adv Drug Deliv Rev 2014;75:18-31.

43. Atkins PJ. Dry powder inhalers: An overview. Respir Care 2005;50:1304-12.

44. Rabbani NR, Seville PC. The influence of formulation components on the aerosolisation properties of spray-dried powders. J Control Release 2005;110:130-40.

45. Rabbani NR, Seville PC. The use of amino acids as formulation excipients in lactose based spray-dried powders. J Pharm Pharmacol 2004;56:32-3.

46. Yamamoto A, Okumura S, Fukuda Y, Fukui M, Takahashi K, Muranishi S, et al. Improvement of the pulmonary absorption of (Asu1,7)-eel calcitonin by various absorption enhancers and their pulmonary toxicity in rats. J Pharm Sci 1997;86:1144-7.

47. Zhao M, You Y, Ren Y, Zhang Y, Tang X. Formulation, characteristics and aerosolization performance of azithromycin DPI prepared by spray-drying. Powder Technol 2008;187:214-21.

48. Thorsson L, Geller D. Factors guiding the choice of delivery device for inhaled corticosteroids in the long-term management of stable asthma and COPD: Focus on budesonide. Respir Med 2005;99:836-49.

49. Available from: https://www.medicines.org.uk/emc/medicine/29177. [Last accessed on 2017 Aug 16].

50. Dalby RN, Eicher J, Zierenberg B. Development of respimat ${ }^{\mathbb{B}}$ softmist ${ }^{\mathrm{tm}}$ inhaler and its clinical utility in respiratory disorders. Med Dev 2011;4:145-55.

51. Anderson P. Use of respimat ${ }^{\mathbb{R}}$ soft misttm inhaler in COPD patients. Int J Chron Obstruct Pulmon Dis 2006;1:251-9.

52. Staniforth JN. Pre-formulation aspects of dry powder aerosols. In: Dalby RN, Byron PR, Farr ST, editors. Respiratory Drug Delivery. Vol. 5. Buffalo Grove, IL: Interpharm Press; 1996.

53. Scheuch G, Fischer A. Intelligent Inhalation technology. IPT 2009;29:61-4.

54. Huh AJ, Kwon YJ. "Nanoantibiotics": A new paradigm for treating infectious diseases using nanomaterials in the antibiotics resistant era. J Control Release 2011;156:128-45.

55. Shaji J, Shaikh M. Formulation, optimization, and characterization of biocompatible inhalable d-cycloserine-loaded alginate-chitosan nanoparticles for pulmonary drug delivery. Asian J Pharm Clin Res 2016;9:82-95

56. Vyas SP, Kannan ME, Jain S, Mishra V, Singh P. Design of liposomal aerosols for improved delivery of rifampicin to alveolar macrophages. Int J Pharm 2004;269:37-49.

57. Paranjpe M, Müller-Goymann CC. Nanoparticle-mediated pulmonary drug delivery: A review. Int J Mol Sci 2014;15:5852-73

58. van den Hoven JM, Metselaar JM, Storm G, Beijnen JH, Nuijen B. Cyclodextrin as membrane protectant in spray-drying and freezedrying of PEGylated liposomes. Int J Pharm 2012;438:209-16.

59. Wang Y, Kho K, Cheow WS, Hadinoto K. A comparison between spray dries and spray freeze drying for dry powder inhaler formulation of drug-loaded lipid-polymer hybrid nanoparticles. Int $\mathrm{J}$ Pharm 2012;424:98-106.

60. Ye T, Yu J, Luo Q, Wang S, Chan HK. Inhalable clarithromycin liposomal dry powders using ultrasonic spray freeze drying. Powder Technol 2017;305:63-70. 